\title{
Rapid set up of research centres in a trial in an evolving research governance world
}

\author{
Sharon Ruddock', Bipin Bhakta ${ }^{2}$, Amanda Lilley-Kelly ${ }^{1}$, Suzanne Hartley ${ }^{1 *}$, Lorna Barnard \\ From 2nd Clinical Trials Methodology Conference: Methodology Matters \\ Edinburgh, UK. 18-19 November 2013
}

The Dopamine Augmented Rehabilitation in Stroke (DARS) trial is a double-blind placebo controlled trial investigating impact of co-careldopa/placebo in combination with routine NHS occupational/physical therapy on functional outcome in people with acute stroke. Recruitment to the trial was lower than anticipated and recruitment predictions suggested that we needed to increase the number of recruiting sites from 20 to at least 40 to achieve an acceptable recruitment rate. This needed to be done as soon as possible to impact on recruitment. We will present the strategic plan which was developed to ensure sites opened to recruitment in a short timeframe. Key components included: collaborating with the Stroke Research Network to identify centres which could adhered to the trial protocol, had a track record in obtaining NHS Permissions in a short timeframe and to provide local knowledge to resolve any issues; identifying and engaging with a dedicated contact at each centre to ensure timely identification of issues; recruitment of a dedicated trial co-ordinator to actively manage the set-up process at each site and the use of a central email account to support the influx of queries. Successful implementation of the plan required close collaboration between the local site staff, the SRN Managers and the central trials team. The plan meant that the average time from receiving Expressions of Interest to NHS Permissions was reduced to 4 months and the recruitment rate has steadily increased to an acceptable rate accordingly.

\footnotetext{
Authors' details

'Leeds Institute of Clinical Trials Research, Leeds, UK. ${ }^{2}$ Academic Department
} of Rehabilitation Medicine, Leeds, UK.

Published: 29 November 2013

${ }^{1}$ Leeds Institute of Clinical Trials Research, Leeds, UK Full list of author information is available at the end of the article
doi:10.1186/1745-6215-14-S1-P132

Cite this article as: Ruddock et al:: Rapid set up of research centres in a trial in an evolving research governance world. Trials 2013 14(Suppl 1): P132.
Submit your next manuscript to BioMed Central and take full advantage of:

- Convenient online submission

- Thorough peer review

- No space constraints or color figure charges

- Immediate publication on acceptance

- Inclusion in PubMed, CAS, Scopus and Google Scholar

- Research which is freely available for redistribution

Submit your manuscript at www.biomedcentral.com/submit
() Biomed Central
C Biomed Central 